\title{
Article \\ Development and Evaluation of a Screening Scale for Indirect Trauma Caused by Media Exposure to Social Disasters
}

\author{
Eun Young Choi ${ }^{1}$, Seung-Hye Choi ${ }^{2, *}$ and Haeyoung Lee ${ }^{3, *(1)}$ \\ 1 Department of Nursing, Graduate School of Chung-Ang University, Seoul 06974, Korea; 11351@naver.com \\ 2 College of Nursing, Gachon University, Incheon 21936, Korea \\ 3 Red Cross College of Nursing, Chung-Ang University, Seoul 06974, Korea \\ * Correspondence: hera1004@gachon.ac.kr (S.-H.C.); im0202@cau.ac.kr (H.L.); \\ Tel.: +82-32-820-4212 (S.-H.C.); +82-2-820-5472 (H.L.)
}

Citation: Choi, E.Y.; Choi, S.-H.

Lee, H. Development and Evaluation of a Screening Scale for Indirect Trauma Caused by Media Exposure to Social Disasters. Int. J. Environ. Res. Public Health 2021, 18, 698. https:// doi.org/10.3390/ijerph18020698

Received: 20 October 2020 Accepted: 12 January 2021 Published: 15 January 2021

Publisher's Note: MDPI stays neutral with regard to jurisdictional clai$\mathrm{ms}$ in published maps and institutional affiliations.

Copyright: (C) 2021 by the authors. Licensee MDPI, Basel, Switzerland. This article is an open access article distributed under the terms and conditions of the Creative Commons Attribution (CC BY) license (https:// creativecommons.org/licenses/by/ $4.0 /)$.

\begin{abstract}
As a result of mass media development, disaster-related information, such as the severity of damage, can be easily shared; thus, the issue of consequent indirect trauma has become as important as that of direct trauma. This study developed a scale to measure the degree of indirect trauma caused by media exposure to social disasters and then verified this scale's reliability and validity. Initial items were developed through a literature review; 39 items were selected by examining their content validity and conducting a pretest. To verify the scale's validity and reliability, exploratory factor analyses were conducted, and Cronbach's alpha coefficients were calculated. The explanatory power of the screening scale developed through this study was $62.2 \%$. The scale was ultimately composed of three factors comprising 24 items. Through exploratory factor analyses, factors were identified as "psychological, physical, and behavioral responses to social disasters" (factor 1), "moral resentment due to social disasters" (factor 2), and "a sense of threat to life due to social disasters" (factor 3). Regarding internal reliability, Cronbach's alpha values ranged between 0.85 and 0.96 . Future studies with expanded participant populations are suggested, which could further verify the scale's validity and reliability and complement its shortcomings.
\end{abstract}

Keywords: social disaster; indirect trauma; indirect victims; PTSD; media

\section{Introduction}

A disaster can be defined as "a serious disruption of the functioning of the community or a society causing widespread human, material, economic or environmental losses which exceed the ability of the affected community or society to cope using its own resources" [1]. Disasters are classified into natural disasters, such as typhoons, floods, and earthquakes, and social disasters, including fires, building collapses, explosions, traffic accidents (including aviation and marine accidents), and chemical, biological, or nuclear accidents [2] Disasters can threaten lives, cause economic losses, and damage both mental and physical health [3]. The psychiatric disorder most frequently experienced by disaster survivors is post-traumatic stress disorder (PTSD). PTSD has become an important issue because of the large number of traumatic events that have been occurring, such as terrorist attacks or meteorological disasters. PTSD is characterized by four main dimensions: re-experience, persistent avoidance, arousal after a traumatic event, and cognitive and mood disturbances [4]. Moreover, survivors may also experience acute stress disorder, major depressive disorder, and anxiety disorders [5]. Whereas disaster survivors' physical injuries can be identified and treated immediately, the treatment of mental health problems that are not outwardly apparent is likely to be delayed or overlooked [6].

Regarding mental health problems that can occur after trauma, the characteristics of the traumatic events are important, as are individual subjective perceptions of the events [7]; thus, the risk factors for post-traumatic stress may be present not only following direct trauma, but also for indirect trauma. In modern society in particular, various media 
sources allow disaster-related information, such as the severity and degree of damage, to be shared easily, even among those who are not directly impacted by the disaster. Therefore, the frequency of indirect exposure and the amount of available information have increased, thereby increasing the possibility that indirect trauma will lead to stress, anxiety, or depression [8].

Indeed, many previous domestic and foreign studies reported that exposure to disasters through mass media is related to vicarious trauma experiences and serious psychological trauma [9-13]. In particular, findings that there were no differences between levels of PTSD in those who experienced a tragic disaster firsthand, such as the 9/11 terrorist attacks, and those who were indirectly exposed to the disaster through television-provided supporting evidence for the importance of media-mediated effects from disasters [14]. Furthermore, previous research presented important implications regarding indirect trauma. For example, one study reported that repeated exposure to television broadcasts that vividly convey disaster scenes has larger negative consequences than direct exposure to traumatic events [15], while another study reported that social media channels also lead to PTSD symptoms similar to those engendered by television broadcasts [16]. Additionally, Silver et al. [12] reported that exposure via television to the initial 9/11 terrorist attacks and subsequent Iraq war and exposure frequency were predictors of PTSD symptoms 2-3 years later, and exposure to 9/11-related television broadcasts for more than $4 \mathrm{~h}$ a day and accumulated acute stress were predictive of physical illness 2-3 years later.

Disasters can be neither easily predicted nor avoided but can happen anytime, anywhere, to anyone. Therefore, they are problems that humanity must overcome, and the paradigm for coping with disasters has recently shifted from vulnerability to resilience [17]. Post-traumatic stress has lasting effects on individuals and society, leading to large increases in direct and indirect costs and providing a major obstacle to community recovery following a disaster [18]. Therefore, identifying disaster survivors at high risk for PTSD and classifying them appropriately to prioritize their treatment is the first step in protecting and systematically managing the mental health of disaster survivors [6]. Although this is important for those exposed both directly and indirectly to disasters, since the scale of indirect victims cannot be specified, a scale that will enable screening for individual degrees of indirect trauma should be developed to identify high-risk groups.

To date, various tools that can assess individual mental health following a disaster have been developed [19], including scales for measuring PTSD, depression, and anxiety. Additionally, tools for measuring suicidal ideation or sleep disorders have been generated, and there are also scales to evaluate other symptoms (e.g., anger response, anger rumination) and complex disorders. However, when screening for the degree of indirect damage caused by trauma, it may be difficult to apply existing tools or to properly filter the concepts to be measured, if there are too many scales or they are too complex. Moreover, when measuring trauma caused by social disasters, not only sociocultural differences but also experiences before and after a disaster should be considered, such as the method and amount of media exposure [19]. Furthermore, although it has been reported that indirect trauma has a similar structure and symptomology to PTSD [20], a scale that reflects the unique characteristics of social disasters, such as moral resentment [21], is necessary to properly measure indirect trauma. Therefore, this study developed and verified the validity and reliability of the Scale for Indirect Trauma caused by Media Exposure to Social disaster (SITMES).

\section{Materials and Methods}

This study was conducted in two phases: scale development and verification (Figure 1). 


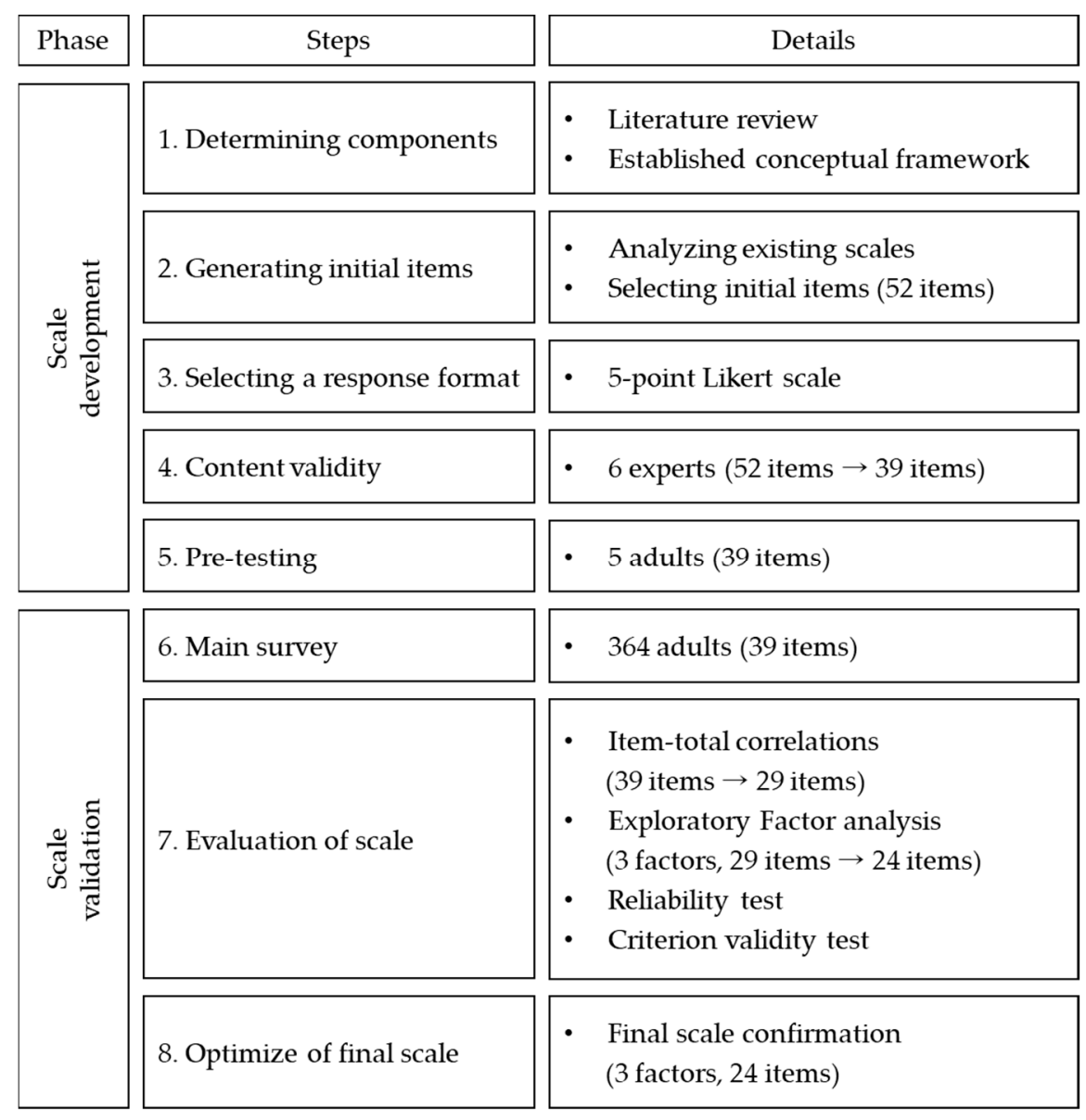

Figure 1. Steps of scale development and validation.

\subsection{Scale Development}

\subsubsection{Determining Components}

To identify scale components, previous studies related to social disasters were reviewed $[13,16,22-30]$. According to the literature review, the symptoms of indirect trauma caused by media exposure to social disasters were identified as psychological, physical, and behavioral responses. However, it was found that even when people experienced the same disaster, factors such as individual characteristics and social support affected the manifestation of trauma symptoms. In particular, in cases where disasters were indirectly experienced through the media, degrees of trauma symptoms differed according to the type and amount of media exposure. However, as existing trauma assessment tools mainly measure symptom severity, efforts were made in the present study to include factors that affect trauma symptoms along with trauma symptoms.

In this study, the conceptual framework was constructed using four concepts based on the Disaster Reintegration Model [22], which emphasizes the importance of resilience in individuals and public support systems to recover from the effects of disasters. Additionally, the 11 components were determined by referring to variables shown to be effective in Lee et al. [26], who provided a meta-analysis of disaster-related variables based on an ecological model.

The four concepts and 11 components were as follows: (a) exposure and response to events (media exposure, psychological symptoms, physical symptoms, and perceived sense of threat to life), (b) individual resilience (trauma experience before the event, stress coping methods, negative emotional responses, and meaning in life and problemsolving), (c) support system (family support and social support), and (d) public resilience (use of information and services). 


\subsubsection{Generating Initial Items}

To develop the initial items, 21 measures related to each component were analyzed $[11,13,16,23,24,30-45]$ (Supplementary Materials). In analyzing each item, the appropriate items were selected for each component. Among them, statements with similar meaning were integrated and the wording modified to suit the purpose of this study. Items related to "use of information and services" were described by the researchers based on Choi et al. [22]. A total of 52 initial items were generated, which were divided among components as follows: media exposure (3), psychological symptoms (7), physical symptoms (3), perceived sense of threat to life (4), trauma experience before the event (3), stress coping methods (10), negative emotional responses (5), meaning in life and problemsolving (4), family support (4), social support (10), and use of information and services (3).

\subsubsection{Selecting a Response Format}

The initial items were measured using a 5-point Likert scale ( $1=$ "Strongly disagree", $2=$ "Disagree", 3 = "Neutral", 4 = "Agree", 5 = "Strongly agree"), with higher scores indicating higher risk of indirect trauma from media-based exposure to social disasters.

\subsubsection{Content Validity}

Content validity of the initial items was reviewed by six experts, consisting of three professors who specialized in mental health nursing, one professor with extensive experience in scale development, and two clinical counseling experts. The expert group was asked to evaluate how appropriately each item measured the degree of indirect trauma caused by media exposure to social disasters using a 4-point Likert scale ( $1=$ "Not at all", $2=$ "Not much", $3=$ "A little", and $4=$ "Very much"), and to review each item's readability and appropriateness of expression.

As a result of the experts' review, eight items with a content validity index (CVI) lower than 0.80 were deleted, and five items with similar meanings were integrated with other items; thus, 39 items were selected in total. The excluded items mainly related to media exposure, trauma experiences before the event, and stress coping methods. Regarding components, media exposure and trauma experiences before the event were integrated into psychological symptoms, meaning in life was integrated into negative emotional responses, and the use of information and services was integrated into problem-solving. The number of items for the modified eight components was as follows: psychological symptoms (9), physical symptoms (3), perceived sense of threat to life (3), negative emotional responses (5), dysfunctional coping methods (5), problem-solving (5), family support (4) and social support (5).

\subsubsection{Pretesting}

A pretest was conducted to identify how well the scale's items could be understood and to evaluate their applicability. Five participants were selected for each age group from the $20 \mathrm{~s}$ to the $60 \mathrm{~s}$, using convenience sampling. The participants provided descriptive feedback regarding items that were difficult to understand or should be corrected.

\subsection{Scale Validation}

\subsubsection{Participants and Procedure}

The study participants included in the validity and reliability analysis of the developed preliminary scale were adults from the general population (age range 20-64 years) who were exposed to social disasters through various forms of media. The exclusion criteria were as follows: (1) people directly exposed to social disasters; (2) people who had not been directly exposed to social disasters, but had a family member, friend, or acquaintance who suffered direct damage from such an event; (3) workers in occupations related to rescue or recovery during social disasters (e.g., medical workers, nurses, mental health professionals, emergency crews, firefighters, police officers), and (4) people who lived in areas where social disasters occurred and who provided assistance to or experienced 
grief with survivors. To filter out participants who met the exclusion criteria, the screening questions were answered at the beginning of the online survey. The recommended sample size for factor analysis is 10 respondents per survey item and/or 200-300 observations [46-49]. In particular, several studies have suggested that a sample size of over 300 is desirable [50,51]. Therefore, we aimed to sample more than 330 respondents, given potential dropout.

Data collection was performed by an approved institution that had no research interest and complied with the code of ethics and research methods of the Korean Association for Survey Research and the Statistic Acts. The survey was conducted from February 19 to 28 February 2020, using an online questionnaire, and the participants were recruited using a survey panel. A total of 377 respondents took the survey, and 364 were included in the final analysis, after 13 questionnaires were excluded due to participants responding based on events other than social disasters (e.g., natural disasters, murders, criminal incidents).

\subsubsection{Measurements}

To verify criterion-related validity of preliminary scales, we used the Korean version of the Impact of Event Scale-Revised (IES-R-K) [52], and the Korean version of the ConnorDavidson Resilience Scale (K-CD-RISC) [53]. The IES-R-K has a total of 22 items, each of which is evaluated on a scale ranging from 0 to 4 points; total scores are calculated by summing individual item scores and range from 0 to 88 points. The internal reliability of the scale was Cronbach's $\alpha=0.93$ originally and 0.98 in this study. The K-CD-RISC has a total of 25 items, and each is evaluated using a 5 -point scale (0-4 points) [46]. Total scores range from 0 to 100 points and are calculated by summing individual item scores; the mean value was analyzed. The internal reliability of the scale was Cronbach's $\alpha=0.93$ originally and 0.94 in this study.

Demographic characteristics included gender, age, level of education, average monthly income, cohabitation status, and employment status. Information regarding exposure to social disasters included the most recent social disaster reported through the media, time elapsed since exposure to the incident, amount of media usage to obtain information regarding the incident, and other psychological difficulties present before exposure to the incident.

\subsubsection{Statistical Analysis}

The data were analyzed using SPSS/WIN 25.0 (IBM Corp., Armonk, NY, USA). Item-level analysis consisted of inter-item and item-total correlations. Items with very low correlations $(<0.30)$ were dropped from the tentative scale [54]. To test construct validity, we used exploratory factor analysis (EFA). The Kaiser-Meyer-Olkin measure of sampling adequacy (KMO) and Bartlett's test of sphericity were used to examine the suitability of the data for EFA. The KMO is an index used to compare the values of observed correlation coefficients with values of partial correlation coefficients; the larger the value, the more common potential factors underlie the measurement variables [55]. In Bartlett's sphericity test, the hypothesis (H0: The correlation coefficient matrix is a unit matrix) was two-sided, tested at a statistical significance level of 0.05. EFA used a maximum likelihood (ML) factor extraction method with direct oblimin rotation to find factor patterns that could be interpreted as factors. We also considered Kaiser's eigenvalue rule [56], scree plots [57], and the minimum average partial (MAP) test [58] to determine the number of factors. Subsequently, items with factor loadings below 0.4 or items with cross loadings greater than 0.3 were dropped [54]. To verify the reliability of the scales, Cronbach's alpha values were obtained. Pearson's correlations were obtained between the factors of SITMES, IES-R-K, and K-CD-RISC to verify the criterion validity of SITMES. Correlations between individual scores were analyzed, and scales with higher degrees of correlation (larger correlation coefficients) were judged to have higher criterion validity. The data on participants ${ }^{\prime}$ demographic characteristics and information on exposure to social disasters were analyzed using descriptive statistics, and the differences in SITMES scores according to participants' 
demographic characteristics and information on exposure to social disasters were analyzed using t-tests and one-way ANOVAs. Post hoc analyses were conducted using Scheffé's test.

\subsection{Ethics}

The study was approved by the Institutional Review Board (IRB no 1041078-201912HRSB-376-01C) of the $C$ university. Potential ethical issues were addressed, including plagiarism, informed consent, misconduct, data fabrication and/or falsification, double publication and/or submission, and redundancy.

\section{Results}

\subsection{Participants' Characteristics}

Of the 364 total participants, 188 (51.65\%) were men and 176 (48.35\%) were women; the mean participant's age was $40.49 \pm 10.99$ years. Regarding level of education, no participant had a middle school graduation or lower level, and college graduates accounted for the largest percentage $(65.11 \%)$. In terms of average monthly income, the largest group included those with an income of 3-6 million won (42.48\%). Most participants lived with family members $(84.62 \%)$, while $13.19 \%$ lived alone. Regarding employment status, wage earners were the group with the highest percentage $(63.74 \%)$.

Among the most recent social disasters reported in the media, infectious diseases/ viruses accounted for the highest percentage $(48.35 \%)$, followed by accidents such as airplane collisions/ship accidents (37.64\%), fires/building collapses $(8.79 \%)$, nuclear accidents/industrial disasters/toxic substances accidents/hydrogen explosions/gas explosions $(3.57 \%)$, and violent situations $(1.65 \%)$. The largest group of participants recollected an event that occurred within the previous month (61.54\%), followed by $1-3$ months $(25.55 \%)$. Regarding the duration of time over which media sources were used to obtain information related to the incidents, the response "a little longer (compared to normal)" was the most frequent $(33.79 \%)$. Regarding whether respondents experienced psychological difficulties related to other incidents before the relevant incident, $24.45 \%$ and $75.55 \%$ answered "yes" and "no", respectively (Table 1). 
Table 1. Differences of SITMES scores according to participant's characteristics.

\begin{tabular}{|c|c|c|c|c|c|c|c|c|c|c|c|c|c|c|}
\hline \multirow{2}{*}{ Variables } & \multirow{2}{*}{ Categories } & \multirow{2}{*}{$N(\%)$} & \multicolumn{3}{|c|}{ Total } & \multicolumn{3}{|c|}{ Factor 1} & \multicolumn{3}{|c|}{ Factor 2} & \multicolumn{3}{|c|}{ Factor 3} \\
\hline & & & $\mathbf{M} \pm \mathbf{S D}$ & $\mathrm{F}(p)$ & Scheffé & $\mathbf{M} \pm \mathbf{S D}$ & $\mathrm{F}(p)$ & Scheffé & $\mathbf{M} \pm \mathbf{S D}$ & $\mathrm{F}(p)$ & Scheffé & $\mathbf{M} \pm \mathbf{S D}$ & $\mathrm{F}(p)$ & Scheffé \\
\hline \multicolumn{15}{|c|}{ Demographic Characteristics } \\
\hline \multirow{4}{*}{ Age (years) } & (1) 19-29 & $82(22.53)$ & $2.45 \pm 0.84$ & \multirow{4}{*}{$\begin{array}{l}3.62 \\
(0.01)\end{array}$} & \multirow{4}{*}{$4>1$} & $1.93 \pm 0.80$ & \multirow{4}{*}{$\begin{array}{l}4.32 \\
(0.01)\end{array}$} & \multirow{4}{*}{$3,4>1$} & $2.55 \pm 1.01$ & \multirow{4}{*}{\multicolumn{2}{|c|}{$\begin{array}{l}1.68 \\
(0.17)\end{array}$}} & $2.88 \pm 1.07$ & \multirow{4}{*}{$\begin{array}{l}3.73 \\
(0.01)\end{array}$} & \multirow{4}{*}{$4>1$} \\
\hline & (2) 30-39 & $83(22.8)$ & $2.71 \pm 0.85$ & & & $2.11 \pm 0.93$ & & & $2.85 \pm 1.05$ & & & $3.19 \pm 0.99$ & & \\
\hline & (3) $40-49$ & $98(26.92)$ & $2.75 \pm 0.88$ & & & $2.29 \pm 0.93$ & & & $2.79 \pm 1.02$ & & & $3.16 \pm 0.98$ & & \\
\hline & (4) $50-59$ & $101(27.75)$ & $2.84 \pm 0.71$ & & & $2.34 \pm 0.76$ & & & $2.84 \pm 0.93$ & & & $3.35 \pm 0.76$ & & \\
\hline \multirow{2}{*}{ Gender } & (1) Male & $188(51.65)$ & $2.67 \pm 0.87$ & \multirow{2}{*}{$\begin{array}{c}0.59 \\
(0.45)\end{array}$} & & $2.21 \pm 0.93$ & \multirow{2}{*}{$\begin{array}{c}0.33 \\
(0.57)\end{array}$} & & $2.72 \pm 1.02$ & \multirow{2}{*}{$\begin{array}{l}0.57 \\
(0.45)\end{array}$} & & $3.07 \pm 0.96$ & \multirow{2}{*}{$\begin{array}{l}2.96 \\
(0.09)\end{array}$} & \\
\hline & (2) Female & $176(48.35)$ & $2.73 \pm 0.79$ & & & $2.15 \pm 0.81$ & & & $2.80 \pm 0.99$ & & & $3.24 \pm 0.96$ & & \\
\hline \multirow{6}{*}{ Education } & (1) Elementary or less & $0(0.00)$ & $0.00 \pm 0.00$ & \multirow{6}{*}{$\begin{array}{l}1.00 \\
(0.40)\end{array}$} & & $0.00 \pm 0.00$ & \multirow{6}{*}{$\begin{array}{l}1.03 \\
(0.38)\end{array}$} & & $0.00 \pm 0.00$ & \multirow{6}{*}{$\begin{array}{l}1.19 \\
(0.31)\end{array}$} & & $0.00 \pm 0.00$ & \multirow{6}{*}{$\begin{array}{l}1.10 \\
(0.35)\end{array}$} & \\
\hline & (2) Middle school & $0(0.00)$ & $0.00 \pm 0.00$ & & & $0.00 \pm 0.00$ & & & $0.00 \pm 0.00$ & & & $0.00 \pm 0.00$ & & \\
\hline & (3) High school & $47(12.91)$ & $2.61 \pm 0.95$ & & & $2.25 \pm 1.00$ & & & $2.58 \pm 1.04$ & & & $3.00 \pm 1.03$ & & \\
\hline & $\begin{array}{l}\text { (4) Attending college or } \\
\text { university }\end{array}$ & $41(11.26)$ & $2.53 \pm 0.87$ & & & $2.01 \pm 0.84$ & & & $2.59 \pm 0.98$ & & & $2.99 \pm 1.13$ & & \\
\hline & (5) College graduation & $237(65.11)$ & $2.75 \pm 0.81$ & & & $2.22 \pm 0.84$ & & & $2.81 \pm 1.00$ & & & $3.21 \pm 0.92$ & & \\
\hline & (6) Graduate school & $39(10.71)$ & $2.70 \pm 0.78$ & & & $2.06 \pm 0.91$ & & & $2.85 \pm 1.02$ & & & $3.18 \pm 0.89$ & & \\
\hline \multirow{5}{*}{ Monthly income (KRW) } & (1) Less than 1 million & $43(11.81)$ & $2.42 \pm 0.99$ & \multirow{5}{*}{$\begin{array}{l}1.83 \\
(0.12)\end{array}$} & & $1.89 \pm 0.97$ & & & $2.64 \pm 1.17$ & & & $2.74 \pm 1.18$ & & \\
\hline & $\begin{array}{l}\text { (2) } 1 \text { million-less than } 3 \\
\text { million }\end{array}$ & $130(35.71)$ & $2.71 \pm 0.79$ & & & $2.14 \pm 0.80$ & & & $2.79 \pm 1.00$ & & & $3.22 \pm 0.93$ & & \\
\hline & $\begin{array}{l}\text { (3) } 3 \text { million-less than } 6 \\
\text { million }\end{array}$ & $155(42.58)$ & $2.75 \pm 0.82$ & & & $2.27 \pm 0.89$ & $\begin{array}{c}2.57 \\
(0.04)\end{array}$ & & $2.77 \pm 0.97$ & $\begin{array}{c}0.36 \\
(0.84)\end{array}$ & & $3.19 \pm 0.92$ & $\begin{array}{l}2.61 \\
(0.04)\end{array}$ & \\
\hline & $\begin{array}{l}\text { (4) } 6 \text { million-less than } 8 \\
\text { million }\end{array}$ & $22(6.05)$ & $2.91 \pm 0.77$ & & & $2.48 \pm 0.85$ & & & $2.88 \pm 0.90$ & & & $3.39 \pm 0.79$ & & \\
\hline & (5) More than 8 million & $14(3.85)$ & $2.54 \pm 0.82$ & & & $2.00 \pm 0.78$ & & & $2.59 \pm 1.07$ & & & $3.04 \pm 0.99$ & & \\
\hline & (1) Living alone & 48 (13.19) & $2.56 \pm 0.90$ & & & $2.07 \pm 0.93$ & & & $2.68 \pm 1.07$ & & & $2.93 \pm 1.07$ & & \\
\hline Cohabitant & (2) Living with family & $308(84.62)$ & $2.73 \pm 0.82$ & 1.30 & & $2.21 \pm 0.86$ & 1.03 & & $2.77 \pm 1.00$ & 0.17 & & $3.20 \pm 0.94$ & $\begin{array}{l}2.79 \\
0.796\end{array}$ & \\
\hline & (3) Living with friend(s) & $8(2.2)$ & $2.42 \pm 0.71$ & & & $1.88 \pm 0.97$ & & & $2.73 \pm 1.10$ & & & $2.66 \pm 0.78$ & & \\
\hline & (1) Self-employed & $34(9.34)$ & $2.73 \pm 0.71$ & & & $2.24 \pm 0.77$ & & & $2.75 \pm 0.79$ & & & $3.21 \pm 0.91$ & & \\
\hline & (2) Wage worker & $232(63.74)$ & $2.72 \pm 0.82$ & & & $2.20 \pm 0.86$ & & & $2.77 \pm 1.00$ & & & $3.18 \pm 0.92$ & & \\
\hline Occupation & (3) Student & $37(10.16)$ & $2.44 \pm 0.85$ & 1.22 & & $1.89 \pm 0.83$ & 1.30 & & $2.59 \pm 1.01$ & 0.39 & & $2.84 \pm 1.14$ & 1.56 & \\
\hline & (4) Housewife & $38(10.44)$ & $2.84 \pm 0.88$ & & & $2.30 \pm 0.93$ & & & $2.88 \pm 1.14$ & & & $3.34 \pm 0.97$ & & \\
\hline & (5) Unemployed & $23(6.32)$ & $2.66 \pm 1.00$ & & & $2.19 \pm 1.01$ & & & $2.78 \pm 1.16$ & & & $3.02 \pm 1.04$ & & \\
\hline
\end{tabular}


Table 1. Cont.

\begin{tabular}{|c|c|c|c|c|c|c|c|c|c|c|c|c|c|c|}
\hline \multirow{2}{*}{ Variables } & \multirow{2}{*}{ Categories } & \multirow{2}{*}{$N(\%)$} & \multicolumn{3}{|c|}{ Total } & \multicolumn{3}{|c|}{ Factor 1} & \multicolumn{3}{|c|}{ Factor 2} & \multicolumn{3}{|c|}{ Factor 3} \\
\hline & & & $\mathbf{M} \pm \mathbf{S D}$ & $\mathrm{F}(p)$ & Scheffé & $\mathbf{M} \pm \mathbf{S D}$ & $\mathbf{F}(p)$ & Scheffé & $\mathbf{M} \pm \mathbf{S D}$ & $\mathbf{F}(p)$ & Scheffé & $\mathbf{M} \pm \mathbf{S D}$ & $F(p)$ & Scheffé \\
\hline \multicolumn{15}{|c|}{ Information of exposure to social disaster } \\
\hline \multirow{5}{*}{$\begin{array}{l}\text { The most recent } \\
\text { incident as Social } \\
\text { disaster through the } \\
\text { media }\end{array}$} & $\begin{array}{l}\text { (1) Infectious } \\
\text { disease/viral infection }\end{array}$ & $176(48.35)$ & $2.89 \pm 0.76$ & \multirow{5}{*}{$\begin{array}{c}5.35 \\
(<0.01)\end{array}$} & \multirow{5}{*}{$1>2$} & $2.34 \pm 0.85$ & \multirow{5}{*}{$\begin{array}{c}4.21 \\
(<0.01)\end{array}$} & \multirow{5}{*}{$1>2$} & $2.97 \pm 0.93$ & \multirow{5}{*}{$\begin{array}{c}4.36 \\
(<0.01)\end{array}$} & \multirow{5}{*}{$1>2$} & $3.36 \pm 0.87$ & \multirow{5}{*}{$\begin{array}{c}4.45 \\
(<0.01)\end{array}$} & \multirow{5}{*}{$1>2$} \\
\hline & $\begin{array}{l}\text { (2) Traffic } \\
\text { accidents/aviation } \\
\text { accidents/marine } \\
\text { accidents }\end{array}$ & $137(37.64)$ & $2.50 \pm 0.86$ & & & $1.98 \pm 0.82$ & & & $2.55 \pm 1.07$ & & & $2.98 \pm 1.01$ & & \\
\hline & $\begin{array}{l}\text { (3) Nuclear } \\
\text { accident/industrial } \\
\text { disaster/toxic substance } \\
\text { accident/hydrogen } \\
\text { explosion/gas explosion }\end{array}$ & $13(3.57)$ & $2.83 \pm 0.95$ & & & $2.38 \pm 1.14$ & & & $2.89 \pm 0.93$ & & & $3.21 \pm 0.97$ & & \\
\hline & $\begin{array}{l}\text { (4) Ter- } \\
\text { ror/bombing/violence }\end{array}$ & $6(1.65)$ & $2.62 \pm 0.74$ & & & $2.49 \pm 0.81$ & & & $2.70 \pm 0.76$ & & & $2.67 \pm 0.86$ & & \\
\hline & (5) Fire/building collapse & $32(8.79)$ & $2.45 \pm 0.84$ & & & $2.02 \pm 0.88$ & & & $2.46 \pm 0.95$ & & & $2.85 \pm 1.03$ & & \\
\hline \multirow{6}{*}{$\begin{array}{l}\text { Elapsed period since } \\
\text { exposure of the incident }\end{array}$} & (1) Less than 1 month & $224(61.54)$ & $2.63 \pm 0.81$ & \multirow{6}{*}{$\begin{array}{l}1.15 \\
(0.34)\end{array}$} & & $2.17 \pm 0.84$ & \multirow{6}{*}{$\begin{array}{c}0.34 \\
(0.89)\end{array}$} & & $2.63 \pm 0.97$ & \multirow{6}{*}{$\begin{array}{c}3.31 \\
(0.01)\end{array}$} & \multirow{6}{*}{$6>1$} & $3.10 \pm 0.94$ & \multirow{6}{*}{$\begin{array}{l}0.97 \\
(0.44)\end{array}$} & \\
\hline & $\begin{array}{l}\text { (2) } 1 \text { month-less than } 3 \\
\text { months }\end{array}$ & $93(25.55)$ & $2.79 \pm 0.83$ & & & $2.16 \pm 0.89$ & & & $2.92 \pm 1.00$ & & & $3.31 \pm 0.96$ & & \\
\hline & $\begin{array}{l}\text { (3) } 3 \text { months-less than } 6 \\
\text { months }\end{array}$ & $7(1.92)$ & $2.78 \pm 0.58$ & & & $2.46 \pm 0.69$ & & & $2.57 \pm 0.69$ & & & $3.32 \pm 0.66$ & & \\
\hline & $\begin{array}{l}\text { (4) } 6 \text { months-less than } 3 \\
\text { years }\end{array}$ & $13(3.57)$ & $2.58 \pm 0.77$ & & & $2.06 \pm 0.81$ & & & $2.80 \pm 0.70$ & & & $2.87 \pm 1.11$ & & \\
\hline & $\begin{array}{l}\text { (5) } 3 \text { years-less than } 5 \\
\text { years }\end{array}$ & $7(1.92)$ & $2.78 \pm 1.29$ & & & $2.11 \pm 1.32$ & & & $3.20 \pm 1.59$ & & & $3.04 \pm 1.22$ & & \\
\hline & (6) More than 5 years & $20(5.49)$ & $3.00 \pm 0.96$ & & & $2.34 \pm 1.03$ & & & $3.41 \pm 1.15$ & & & $3.26 \pm 1.07$ & & \\
\hline \multirow{5}{*}{$\begin{array}{l}\text { Amount of media usage } \\
\text { to obtain information } \\
\text { the incident }\end{array}$} & $\begin{array}{l}\text { (1) Significantly shorter } \\
\text { (than usual) }\end{array}$ & $38(10.44)$ & $2.04 \pm 0.82$ & \multirow{5}{*}{$\begin{array}{c}20.03 \\
(<0.01)\end{array}$} & \multirow{5}{*}{$\begin{aligned} 5 & >1-4 \\
4 & >1,3 \\
3 & >1 \\
2 & >1\end{aligned}$} & $1.60 \pm 0.78$ & \multirow{5}{*}{$\begin{array}{l}10.26 \\
(<0.01)\end{array}$} & \multirow{5}{*}{$\begin{array}{l}5>1-3 \\
4,3>1\end{array}$} & $2.03 \pm 0.91$ & \multirow{5}{*}{$\begin{array}{l}18.01 \\
(<0.01)\end{array}$} & \multirow{5}{*}{$\begin{array}{c}5>1-4 \\
4>1\end{array}$} & $2.49 \pm 1.12$ & \multirow{5}{*}{$\begin{array}{l}19.29 \\
(<0.01)\end{array}$} & \\
\hline & $\begin{array}{l}\text { (2) Slightly shorter (than } \\
\text { usual) }\end{array}$ & $47(12.91)$ & $2.57 \pm 0.88$ & & & $1.95 \pm 0.91$ & & & $2.63 \pm 1.12$ & & & $3.12 \pm 1.00$ & & \\
\hline & (3) Similar (as usual) & $107(29.40)$ & $2.52 \pm 0.74$ & & & $2.12 \pm 0.79$ & & & $2.54 \pm 0.85$ & & & $2.90 \pm 0.88$ & & $\begin{array}{l}5>1-4 \\
4>1,3\end{array}$ \\
\hline & $\begin{array}{l}\text { (4) Slightly longer (than } \\
\text { usual) }\end{array}$ & $123(33.79)$ & $2.84 \pm 0.69$ & & & $2.33 \pm 0.76$ & & & $2.91 \pm 0.88$ & & & $3.28 \pm 0.81$ & & \\
\hline & $\begin{array}{l}\text { (5) Significantly longer } \\
\text { (than usual) }\end{array}$ & $49(13.46)$ & $3.38 \pm 0.77$ & & & $2.63 \pm 1.02$ & & & $3.57 \pm 0.97$ & & & $3.93 \pm 0.72$ & & \\
\hline Other psychological & (1) Yes & $89(24.45)$ & $3.07 \pm 0.71$ & 24.68 & & $2.52 \pm 0.84$ & 19.23 & & $3.14 \pm 0.95$ & 4.21 & & $3.54 \pm 0.73$ & 5.16 & \\
\hline exposure of the incident & (2) No & $275(75.55)$ & $2.58 \pm 0.83$ & $(<0.01)$ & & $2.07 \pm 0.85$ & $(<0.01)$ & & $2.64 \pm 0.99$ & & & $3.03 \pm 0.99$ & $(<0.01)$ & \\
\hline
\end{tabular}

Abbreviations: SITMES, Screening scale for Indirect Trauma caused by Media Exposure to Social disaster; M, Mean; SD, Standard Deviation 


\subsection{Evaluation of Scale}

\subsubsection{Item Analysis}

The correlation coefficients between all items and an individual item were obtained. Items with a correlation coefficient of 0.3 or less and items with inverse correlations were deleted, as they had a weak contribution. As a result, 10 items $(26,27,28,29,30,31,32,34$, $36,37)$ with inverse correlations were deleted. Inter-item correlations for 29 items ranged from 0.22 to 0.81 .

\subsubsection{Construct Validity Test}

First, EFA was conducted with 29 items. The factor analysis produced three factors with eigenvalues $>1(15.759,2.395,1.054)$ and the cumulative variance explained was $62.2 \%$. The scree plot showed that the slope of the curve exhibited a discontinuity at three factors and the MAP test result also supported the existence of three factors. Thus, we selected three factors.

In the first EFA, the KMO value was 0.97 and the Bartlett's test statistic value was $8882.47(p<0.001)$. In the pattern matrix, there were no items with factor loadings below 0.4 , but items 4,6 , and 17 were deleted, as they exhibited factor loadings of 0.3 or higher on more than two factors.

The second EFA was conducted with 26 items. The KMO value was 0.96 and Bartlett's test statistic was $7518.42(p<0.001)$. In pattern matrix, items 15 and 25 were deleted, due to factor loadings below 0.4 , but no items exhibited cross factor loadings of 0.3 or higher.

The third EFA was conducted with 24 items. The KMO value was 0.96 and Bartlett's test statistic was $7042.93(p<0.001)$. In this round, all items met the factor loading criteria. The results of the final EFA are shown in Table 2. 
Table 2. The results of final exploratory factor analysis.

\begin{tabular}{|c|c|c|c|c|}
\hline No. & Items & Factor 1 & Factor 2 & Factor 3 \\
\hline 3 & I used to dream about the incident. & 0.77 & & \\
\hline 5 & After the incident, I felt lonely, as if I was alone in the world. & 0.77 & & \\
\hline 7 & $\begin{array}{l}\text { After the incident, it has become difficult for me to concentrate on everyday tasks, } \\
\text { such as reading a newspaper or watching TV. }\end{array}$ & 0.80 & & \\
\hline 8 & $\begin{array}{l}\text { I started to avoid news or conversations related to the incident because I do not want } \\
\text { to gain more information about it. }\end{array}$ & 0.72 & & \\
\hline 9 & The incident made me suffer even more as I recalled past traumatic experiences. & 0.80 & & \\
\hline 10 & After that incident, I have not been able to sleep. & 0.91 & & \\
\hline 11 & $\begin{array}{l}\text { When I thought of the incident, symptoms such as dizziness, difficulty breathing, } \\
\text { cold sweat, and body stiffness occurred. }\end{array}$ & 0.92 & & \\
\hline 12 & After the incident, I lost my appetite. & 0.88 & & \\
\hline 21 & I drank to forget my feelings about the incident. & 0.80 & & \\
\hline 23 & I tried not to believe the incident happened. & 0.55 & & \\
\hline 24 & I worked or performed other activities to forget my feelings about the incident. & 0.77 & & \\
\hline 33 & My family members hate when I talk about the incident. & 0.75 & & \\
\hline 35 & There was no one with whom I could share my feelings about the incident. & 0.70 & & \\
\hline 38 & After the incident, I was disappointed in those who were supposed to support me. & 0.80 & & \\
\hline 39 & After the incident, I tried to be alone rather than around other people. & 0.64 & & \\
\hline 16 & I was upset when I recalled things or people related to the incident. & & 0.58 & \\
\hline 18 & I felt skeptical that the incident took place due to widespread irresponsibility in society. & & 0.75 & \\
\hline 19 & Because of the incident, I felt that the world was unjust. & & 0.92 & \\
\hline 20 & When I thought about the incident, I felt resentment and indignation. & & 0.72 & \\
\hline 22 & 1 expressed negative feelings about the incident. & & 0.48 & \\
\hline 1 & $\begin{array}{l}\text { When I thought about the incident, I felt emotions such as depression, sadness, } \\
\text { and fear. }\end{array}$ & & & 0.67 \\
\hline 2 & I used to have unwanted painful thoughts or images about the incident. & & & 0.66 \\
\hline 13 & $\begin{array}{l}\text { I thought that something similar to the incident might happen to me or someone close } \\
\text { to me. }\end{array}$ & & & 0.62 \\
\hline 14 & I became wary of situations, objects, and people similar to the incident. & & & 0.49 \\
\hline & Eigenvalues & 13.08 & 2.26 & 0.96 \\
\hline & Explained proportion (\%) & 52.92 & 7.85 & 2.55 \\
\hline & Cumulative proportion (\%) & 52.92 & 60.77 & 63.31 \\
\hline
\end{tabular}

Notes: If the factor loading was less than 0.4 , it is not shown in this table.

\subsubsection{Factor Naming}

Items were analyzed by factor to name the factors, with 15 items grouped into factor 1 , which explained the largest proportion of variance. The items of factor 1 were those used in previous studies to measure physical symptoms, psychological symptoms, dysfunctional coping methods, and the effects of media exposure or traumatic experiences. Therefore, factor 1 was named "psychological, physical, and behavioral responses to social disasters." Factor 2 comprised five items, including those used to measure negative emotional reactions and anger and skepticism toward society, among those measuring dysfunctional coping methods. Therefore, factor 2 was named "moral resentment due to social disasters." Factor 3 comprised four items, including those used to measure psychological symptoms 
and perceived threat to life. Therefore, factor 3 was named "a sense of threat to life due to social disasters."

\subsubsection{Reliability Test}

Regarding internal consistency reliability of the 24 items of SITMES, Cronbach's $\alpha=0.96$. Inter-item reliability for the scale's three factors was analyzed; the results indicated high reliability: Cronbach's $\alpha=0.96,0.89$, and 0.85 for factors 1,2 , and 3 , respectively (Table 3).

Table 3. The results of reliability test.

\begin{tabular}{|c|c|c|c|c|}
\hline Factor & No. of Item & $\begin{array}{l}\text { Corrected Item-Total } \\
\text { Correlation }\end{array}$ & $\begin{array}{l}\text { Cronbach's Alpha } \\
\text { for Deleted Item }\end{array}$ & $\begin{array}{c}\text { Total Cronbach's } \\
\text { Alpha }\end{array}$ \\
\hline \multirow{15}{*}{$\begin{array}{l}\text { Factor 1: psychological, physical, } \\
\text { and behavioral responses to } \\
\text { social disasters }\end{array}$} & 3 & 0.76 & 0.96 & \multirow{15}{*}{0.96} \\
\hline & 5 & 0.81 & 0.96 & \\
\hline & 7 & 0.83 & 0.96 & \\
\hline & 8 & 0.75 & 0.96 & \\
\hline & 9 & 0.79 & 0.96 & \\
\hline & 10 & 0.83 & 0.96 & \\
\hline & 11 & 0.84 & 0.96 & \\
\hline & 12 & 0.84 & 0.96 & \\
\hline & 21 & 0.77 & 0.96 & \\
\hline & 23 & 0.69 & 0.96 & \\
\hline & 24 & 0.82 & 0.96 & \\
\hline & 33 & 0.76 & 0.96 & \\
\hline & 35 & 0.69 & 0.96 & \\
\hline & 38 & 0.79 & 0.96 & \\
\hline & 39 & 0.71 & 0.96 & \\
\hline \multirow{5}{*}{$\begin{array}{l}\text { Factor 2: moral resentment due to } \\
\text { social disasters }\end{array}$} & 16 & 0.71 & 0.87 & \multirow{5}{*}{0.89} \\
\hline & 18 & 0.74 & 0.86 & \\
\hline & 19 & 0.78 & 0.86 & \\
\hline & 20 & 0.79 & 0.86 & \\
\hline & 22 & 0.65 & 0.89 & \\
\hline \multirow{4}{*}{$\begin{array}{c}\text { Factor 3: a sense of threat to life due to } \\
\text { social disasters }\end{array}$} & 1 & 0.71 & 0.80 & \multirow{4}{*}{0.85} \\
\hline & 2 & 0.72 & 0.80 & \\
\hline & 13 & 0.67 & 0.82 & \\
\hline & 14 & 0.67 & 0.82 & \\
\hline
\end{tabular}

\subsubsection{Criterion Validity Test}

The correlations between indirect trauma and the three factors measured with the finalized version of SITMES, IES-R-K, and K-CD-RISC are shown in Table 4. Scores of SITMES showed a significant correlation with the results of the IES-R-K $(r=0.69, p<0.01)$; however, SITMES scores had no significant correlation with K-CD-RISC.

Table 4. Correlation between SITMES and other measures for criterion validity.

\begin{tabular}{ccccc}
\hline Variables & SITMES & F1 & F2 & F3 \\
\hline IES-R-K & $0.69^{*}$ & $0.76^{*}$ & $0.57^{*}$ & $0.51^{*}$ \\
K-CD-RISC & 0.05 & 0.01 & 0.05 & 0.06
\end{tabular}

Notes: ${ }^{*} p<0.01$. Abbreviations: IES-R-K, Korean version of the Impact of Event Scale-Revised; K-CD-RISC, Korean version of Connor-Davidson Resilience Scale; SITMES, Screening scale for Indirect Trauma caused by Media Exposure to Social disaster.

\subsection{Differences in SITMES Scores According to Participant's Characteristics}

The differences in SITMES scores according to participants' demographic characteristics and information on exposure to social disasters were analyzed. Accordingly, no differ- 
ences were found in SITMES scores according to gender, level of education, or income level; however, there were significant differences according to age $(\mathrm{F}=3.62, p=0.01)$, as older age was positively associated with greater SITMES scores. When differences in SITMES scores according to incident type were analyzed, the results indicated that the SITMES scores related to an "infectious disease/virus" were greater than those for "airplane collision/ship accidents/traffic accidents" ( $\mathrm{F}=5.35, p \leq 0.01)$. SITMES scores were also higher among participants who spent more time using media to obtain information related to an incident, compared with those who spent less time on this activity $(\mathrm{F}=20.03, p \leq 0.01)$. SITMES scores were higher for those who had experienced psychological difficulties before an incident than among those who had not $(\mathrm{F}=24.68, p \leq 0.01$; Table 1).

\section{Discussion}

The SITMES, developed in this study, consists of three factors and 24 items. The first factor was "psychological, physical, and behavioral responses to social disasters", comprising 16 items, which was identified as the most important factor because it explained the largest proportion of response variance. This was thought to be attributable to trauma symptoms appearing in mixture in diverse aspects. According to a previous study, media-mediated experiences of disasters emerge via physical and physiological stress activation mechanisms. That is, when people are shown images of traumatic events by media, fear circuits of the brain activate and generate flashbacks, which are key processes in PTSD [16]. In particular, the integration of trauma coping capabilities into this factor supports the study's findings indicating that this factor affects the expression of trauma symptoms $[12,24,26]$.

The second factor, consisting of five items, was "moral resentment due to social disasters." A characteristic of emotional responses to social disasters is to experience moral resentment at the occurrence of the incident, in addition to mental health outcomes, such as PTSD. Moral resentment is an emotion that enables moral judgment and leads individuals to seek the legitimacy of punishment for unjust acts. Therefore, moral resentment causes social changes powered by righteous indignation and motivated by the desire to restore justice [21]. In particular, negative emotional responses can be expressed not only as anger but also as grudges or resentment, which can be viewed as a response similar to post-traumatic embitterment disorder [59].

The third factor was "a sense of threat to life due to social disasters", and comprised four items. This factor was related to the belief that an incident similar to the social disaster may occur to oneself, family members, or friends, and can be seen as a result of empathizing with the victim or the victim's family [23]. With the development of information and communications technology (ICT), modern people are connected to various media $24 \mathrm{~h}$ per day [16]. In an uncertain and threatening disaster crisis, people actively seek information and depend on the media to determine the cause and effects of the disaster [16]. This is consistent with a previous study indicating that media exposure can cause indirect trauma symptoms even when the relevant person is geographically and temporally far away from a social disaster [60].

The correlation between the IES-R-K and K-CD-RISC was analyzed to verify the scale's criterion validity. The scores obtained using the SITMES showed a positive correlation with the incident impact scale scores, particularly a high positive correlation with the first factor. This indicated that the developed scale could meaningfully reflect degrees of indirect trauma caused by media exposure to social disasters. However, the developed scale did not show any correlation with resilience scores. This may be related to the items that were deleted when verifying the scale's construct validity. The 10 deleted items with inverse correlations corresponded to problem-solving or family or social support among trauma-coping competency, and all were inverse conversion items, for which higher scores indicated higher levels of capabilities or support. These items were expected to reflect factors that reduce indirect trauma; however, they were excluded due to incongruity with other items because of their inverse conversion responses or given that the overall scores 
of participants were not high, the demand for problem-solving capabilities or support systems may have been low because the trauma symptoms were not serious. Moreover, this may be due to participants' family characteristics, which were not closely examined in the present study. Family is a fundamental resource that provides comfort and support for disaster-related trauma, but in some cases, negative interactions may occur among family members [26]. The items related to family or social support were included in factor 1 (items 33, 35, 38, and 39). This is consistent with a conceptual framework in which support systems and the expression of symptoms are related. Including support factors would provide further distinction from existing tools, but since support systems were not categorized as a factor, items may need to be modified or supplemented to reveal such a factor.

As with previous studies, the degree of trauma increased as the amount of media exposure increased $[19,61]$. In addition, the degree of indirect trauma was greater for respondents who experienced trauma before the reported incident, compared to those without previous trauma experience. These items were deleted during expert verification of content validity because they were too ambiguous to be included in the questionnaire. However, these items should be considered when measuring the indirect trauma of social disasters, and studies reflecting them will be necessary in the future.

The results of the present study indicated that the degree of trauma in the middleaged group (50s) was generally higher than in the younger age group (20s). This is consistent with a previous study that indicated older adults are more vulnerable to PTSD symptoms than younger adults, because the former are relatively more likely to have experienced war or personal loss [62]. However, no gender differences were found in trauma scores. Previous research showed women to be more psychologically vulnerable than men regarding degrees of trauma $[19,63,64]$, but other studies found degrees of trauma do not differ according to gender $[14,65]$. This suggests that the scale developed in the present study can discriminate between groups at high and low risk for indirect trauma from social disasters; however, since the results were also shown to conflict with some previous research, such as that regarding gender differences, follow-up studies should be conducted with expanded participant groups. As the limitations of time and space are gradually disappearing due to the development of ICT, indirect trauma caused by social disasters is increasing. The disaster stressor may be a risk factor that amplifies the deleterious impact of media use on mental health [66]. The degree of indirect trauma due to media coverage of disasters is affected by various factors [16]; as such, victims may be unaware of such trauma. SITMES may contribute to determining the extent of indirect damage caused by the media and reducing such damage by enabling early detection of mental problems at the personal level and consequently promoting reduced media exposure at the societal level.

This study has the following limitations. First, given that many respondents chose "infectious disease/virus" as the social disaster they experienced, and the data were collected during a period when COVID-19 was spreading, the characteristics of indirect trauma measured in this study may have been biased toward incidents related to viral infection. Second, although participants were asked to remember a social disaster they recently experienced, the amount of time that had elapsed since the incidents differed among participants; thus, the findings may be affected by recall bias. Third, it is difficult to exclude the possibility of selection bias. A survey panel was used to recruit participants so they would not be limited to a certain group; however, studies conducted with larger participant samples are needed. Fourth, the proportion of individuals with low education in the sample was small. Individuals with low education may be relatively prone to media-induced distress. Additionally, previous real-life exposure was not controlled, nor were other stressors that may have increased the level of distress. Lastly, no cutoff point was presented for the developed scale. To use the SITMES more successfully, follow-up studies that present a cutoff point should be conducted. To overcome these limitations, it is necessary to further refine the scale through confirmatory factor analysis, confirm 
test-retest validity, and target more diverse social disasters. In addition, it is necessary to use longitudinal studies to verify the practical effectiveness of SITMES as a tool to measure indirect trauma due to social disasters.

\section{Conclusions}

In this study, a scale to screen for indirect trauma caused by media exposure to social disasters was developed and evaluated for validity and reliability. The SITMES, consisting of three factors comprising 24 items, was verified to be highly reliable and have appropriate construct validity. Efforts were made to include characteristics of cognitive and emotional responses to social disasters; however, since there may have been selection bias, and the characteristics and effects of social disasters as perceived by participants may have varied according to the time of the surveys, further refinement of the scale is necessary by applying it to a larger participant population and repeatedly verifying its reliability and validity. This study can hopefully contribute to improving community resilience in overcoming disasters by measuring the impact of indirect trauma experienced through media exposure to social disasters and detecting individuals indirectly affected by disasters who are likely to be otherwise overlooked.

Supplementary Materials: The following are available online at https:/ / www.mdpi.com/1660-460 1/18/2/698/s1, Table S1: References for initial items development.

Author Contributions: Conceptualization, E.Y.C. and H.L.; data curation, E.Y.C., S.-H.C. and H.L.; formal analysis, E.Y.C.; funding acquisition, H.L.; methodology, E.Y.C. and H.L.; project administration, H.L.; validation, H.L.; visualization, E.Y.C.; writing-original draft, E.Y.C., S.-H.C. and H.L.; writing-review \& editing, E.Y.C., S.-H.C. and H.L. All authors have read and agreed to the published version of the manuscript.

Funding: This work was supported by the National Research Foundation of Korea (NRF) grant funded by the Korean government (MSIP; Ministry of Science, ICT \& Future Planning) (No. 2018R1C1B5039240).

Institutional Review Board Statement: The study was conducted according to the guidelines of the Declaration of Helsinki, and approved by the Institutional Review Board (or Ethics Committee) of Chung-Ang university (IRB no 1041078-201912-HRSB-376-01C). Ethical issues, including plagiarism, informed consent, misconduct, data fabrication and/or falsification, double publication and/or submission, and redundancy have been thoroughly checked by the authors.

Informed Consent Statement: Participants' consent was waived because data collection was conducted through an anonymous online survey.

Data Availability Statement: The data presented in this study are available on request from the corresponding author.

Acknowledgments: All authors would like to acknowledge the cooperation of the participants in this study.

Conflicts of Interest: The authors declare no conflict of interest.

\section{References}

1. United Nations International Strategy for Disaster Reduction. UNISDR Terminology on Disaster Risk Reduction (p. 9). United Nations International Strategy for Disaster Reduction. 2009. Available online: http://www.unisdr.org/files/7817 _UNISDRTerminologyEnglish.pdf (accessed on 29 January 2019).

2. Korea Ministry of Government Legislation. Misfortune and the Safety Supervision Basic Law. 2018. Available online: http: / / www.law.go.kr/lsSc.do? menuId=0\&p1=\&subMenu=1\&nw Yn=1\&section=\&tabNo=\&query=\%EC $\% 9 \mathrm{E} \% \mathrm{AC} \% \mathrm{~EB} \% 82$ $\% 9 \mathrm{C} \% 20 \% \mathrm{~EB} \% \mathrm{B0} \% 8 \mathrm{~F} \% 20 \% \mathrm{EC} \% 95 \% 88 \% \mathrm{EC} \% \mathrm{A0} \% 84 \% \mathrm{EA} \% \mathrm{~B} 4 \% 80 \% \mathrm{~EB} \% \mathrm{~A} 6 \%$ AC $\% 20 \% \mathrm{EA} \% \mathrm{~B} 8 \% \mathrm{~B} 0 \% \mathrm{~EB} \% \mathrm{~B} 3 \% \mathrm{~B} 8 \% \mathrm{~EB} \% \mathrm{~B} 2 \% 9$ 5\#undefined (accessed on 29 January 2019).

3. Wisnivesky, J.P.; Teitelbaum, S.L.; Todd, A.C.; Boffetta, P.; Crane, M.; Crowley, L.; Kim, H. Persistence of multiple illnesses in World Trade Center rescue and recovery workers: A cohort study. Lancet 2011, 378, 888-897. [CrossRef]

4. Franklin, C.L.; Piazza, V.; Chelminski, I.; Zimmerman, M. Defining subthreshold PTSD in the DSM-IV literature: A look toward DSM-5. J. Nerv. Ment. Dis. 2015, 203, 574-577. [CrossRef] 
5. Fullerton, C.S.; Ursano, R.J.; Wang, L. Acute stress disorder, posttraumatic stress disorder, and depression in disaster or rescue workers. Am. J. Psychiatry 2004, 161, 1370-1376. [CrossRef]

6. North, C.S.; Pfefferbaum, B. Mental health response to community disasters: A systematic review. JAMA 2013, 310, 507-518. [CrossRef]

7. Cukor, J.; Wyka, K.; Mello, B.; Olden, M.; Jayasinghe, N.; Roberts, J.; Difede, J. The longitudinal course of PTSD among disaster workers deployed to the World Trade Center following the attacks of September 11th. J. Trauma. Stress 2011, 24, 506-514. [CrossRef]

8. Neria, Y.; Sullivan, G.M. Un derstanding the mental health effects of indirect exposure to mass trauma through the media. JAMA 2011, 306, 1374-1375. [CrossRef]

9. Ahern, J.; Galea, S.; Resnick, H.; Kilpatrick, D.; Bucuvalas, M.; Gold, J.; Vlahov, D. Television images and psychological symptoms after the September 11 terrorist attacks. Psychiatry: Interpers. Biol. Process. 2002, 65, 289-300. [CrossRef]

10. Ahern, J.; Galea, S.; Resnick, H.; Vlahov, D. Television images and probable posttraumatic stress disorder after September 11: The role of background characteristics, event exposures, and prevent panic. J. Nerv. Ment. Dis. 2004, 192, 217-226. [CrossRef]

11. Lee, H.P.; Choi, Y.K.; Lee, J.H.; Lee, H.S. The psychological consequences of indirect trauma exposure through the news on the Sewol ferry disaster. Korean J. Cult. Soc. Iss. 2016, 22, 411-430. [CrossRef]

12. Silver, R.C.; Holman, E.A.; Andersen, J.P.; Poulin, M.; McIntosh, D.N.; Gil-Rivas, V. Mental-and physical-health effects of acute exposure to media images of the September 11, 2001 attacks and the Iraq War. Psychol. Sci. 2013, 24, 1623-1634. [CrossRef]

13. Sohn, S.H. Study of indirect trauma and related variables by social traumatic event to the adolescence: Focusing on the Sewol ferry disaster. Korean J. Youth Stud. 2014, 21, 269-294.

14. Jarolmen, J.; Sisco, H. Media effects on post-traumatic stress disorder and the world trade center tragedy. Best Pr. Ment. Health 2005, 1, 133-140.

15. Holman, E.A.; Garfin, D.R.; Silver, R.C. Media's role in broadcasting acute stress following the Boston Marathon bombings. Proc. Natl. Acad. Sci. USA 2014, 111, 93-98. [CrossRef] [PubMed]

16. Park, N.; Chang, S.H.; Jeong, J. Media use during the Sewol ferry disaster and posttraumatic stress disorder. J. Digit. Contents Soc. 2018, 19, 673-683. [CrossRef]

17. Bhatia, S. Urban Risk and The Post-2015 Framework on Disaster Risk Reduction. In Proceedings of the 2014 International Conference on Disaster Management, Nagpur, India, 13-14 March 2014.

18. Norris, F.H.; Murphy, A.D.; Baker, C.K.; Perilla, J.L. Postdisaster PTSD over four waves of a panel study of Mexico's 1999 flood. J. Trauma Stress 2004, 17, 283-292. [CrossRef]

19. Park, J.E.; Kang, S.H.; Won, S.D.; Roh, D.; Kim, W.H. Assessment instruments for disaster behavioral health. Anxiety Mood 2015, 11,91-105.

20. Suvak, M.; Maguen, S.; Litz, B.T.; Silver, R.C.; Holman, E.A. Indirect exposure to the September 11 terrorist attacks: Does symptom structure resemble PTSD? J. Trauma. Stress 2008, 21, 30-39. [CrossRef]

21. Yang, S. Moral emotion in the cultural context: The role of sympathy in a Humean moral sentimentalism and the pro-social aspect of guilt and indignation. Hum. Beings Environ. Future 2014, 3, 31-59.

22. Choi, Y.J.; Choi, H.B.; O’Donnell, M. Disaster reintegration model: A qualitative analysis on developing Korean disaster mental health support model. Int. J. Envion. Res. Public Health 2018, 15, 362. [CrossRef]

23. Hur, Y.J.; Rhee, M.K. Development and validation of indirect trauma scale of social disaster. Korea J. Cult. Soc. Iss. 2017, $23,381-407$. [CrossRef]

24. Jeong, U.M. Indirect Trauma Response by Media Exposure of Sewol Ferry Disaster in University Students in Korea; Trauma-Related Negative Beliefs as Moderating Variables. Master's Thesis, Daegu University, Daegu, Korea, 2015.

25. Lee, D.S. The Relationship between Exposure to Disaster through the Media, Coping Strategies, and Secondary Traumatization. Master's Thesis, Ewha Womans University, Seoul, Korea, 2015.

26. Lee, N.B.; Ahn, H.N. A meta-analysis study of predictors of disaster victims post-traumatic stress response based on ecological model. Korean J. Psychol. Gen. 2016, 35, 525-562. [CrossRef]

27. Lee, J.E.; Kim, J.O.; Kim, N.J.; Kim, B.H. The post-traumatic stress disorder based on people's perception type after technological disaster: Focused on Sewol ferry disaster. J. Korean Soc. Sci. Study Subj. 2014, 29, $5-27$.

28. Lee, N.B.; Joo, H.S.; Ahn, H.N. The mediating effects of community resilience in the relationship between world assumption and well-being of the Sewol ferry disaster in the public: Longitudinal analysis. Korean J. Soc. Personal. Psychol. 2016, 31, 37-60.

29. Min, M.K.; Joo, H.S.; Ahn, H.N. Psychosocial factors influential to the mental health of the public indirectly affected by the $9 / 12$ Gyeong-ju earthquake: Focusing on individual resilience, social support, social capital, and public trust. Korean J. Couns. 2018, 19, 93-116.

30. Park, J.Y. Psychometric properties of the Korean version of the secondary traumatic stress scale (K-STSS). Korean J. Soc. Welf. 2011, 63, 33-57. [CrossRef]

31. Ben-Zur, H.; Sharon Gil, Y.; Shamshins, Y. The relationship between exposure to terror through the media, coping strategies and resources, and distress and secondary traumatization. Int. J. Stress Manag. 2012, 19, 132-150. [CrossRef]

32. An, J.Y.; Seo, E.R.; Lim, K.H.; Shin, J.H.; Kim, J.B. Standardization of the Korean version of screening tool for depression (Patient Health Questionnaire-9, PHQ-9). J. Korean Soc. Biol. Psychiatry 2013, 19, 47-56. 
33. Cameron, R.P.; Gusman, D. The primary care PTSD screen (PC-PTSD): Development and operating characteristics. Prim. Care Psychiatry 2003, 9, 9-14.

34. Chon, K.K.; Choi, S.C.; Yang, B.C. Integrated Adaptation of CES-D in Korea. Korean J. Health Psychol. $2001,6,59-76$.

35. Derogatis, L.R.; Savitz, K.L. The SCL-90-R, Brief Symptom Inventory, and Matching Clinical Rating Scales. In The Use of Psychological Testing for Treatment Planning and Outcomes Assessment; Maruish, M.E., Ed.; Lawrence Erlbaum Associates Publishers: Mahwah, NJ, USA, 1999; pp. 679-724.

36. Joo, H.S.; Ahn, H.N. Development and validation of posttrauma risk checklist. Korean J. Psychol. Gen. 2008, $27,235-257$.

37. Nam, B.R.; Kwon, H.I.; Kwon, J.H. Psychometric qualities of the Korean version of the posttraumatic diagnosis scale (PDS-K). Korean J. Clin. Psychol. 2010, 29, 147-167.

38. Lee, H.H.; Kim, E.J.; Lee, M.K. A validation study of Korea positive and negative affect schedule: The PANAS scales. Korean J. Clin. Psychol. 2003, 22, 935-946.

39. Shin, S.Y.; Chung, N.W. The effect of meaning in life and social support on posttraumatic growth: Rumination as a mediating variable. J. Hum. Underst. Couns. 2012, 33, 217-235.

40. Carver, C.S. You want to measure coping but your protocol'too long: Consider the brief cope. Int. J. Behav. Med. 1997, 4, 92. [CrossRef] [PubMed]

41. Park, J.H. Effects of Rumination, Thought Suppression, and Self-Disclosure about the Stressful Life Event on Emotion and Subjective Well-Being. Master's Thesis, Sungkyunkwan University, Seoul, Korea, 2007.

42. Kang, H.S. Experimental Study of the Effects of Reinforcement Education for Rehabilitation on Hemiplegia Patients' Self-Care Activities. Master's Thesis, Yonsei University, Seoul, Korea, 1984.

43. Joseph, S.; Andrews, B.; Williams, R.; Yule, W. Crisis support and psychiatric symptomatology in adult survivors of the Jupiter cruise ship disaster. Br. J. Clin. Psychol. 1992, 31, 63-73. [CrossRef] [PubMed]

44. Seo, S.Y.; Im, Y.S.; Lee, S.H.; Park, M.S.; Yoo, T.W. A study for the development of Korean version of the Duke-UNC functional social support questionnaire. Korean J. Fam. Med. 1997, 18, 250-260.

45. Sim, K.S.; Ahn, H. A validation of the Korean version of the social reactions questionnaire. Korean J. Couns. Psychother. 2014, 26, 271-298.

46. Clarke, L.A.; Watson, D. Constructing validity: Basic issues in objective scale development. Pyschol. Assess. 1995, 7, 309-319. [CrossRef]

47. MacCallum, R.C.; Widaman, K.F.; Zhang, S.; Hong, S. Sample size in factor analysis. Psychol. Methods 1999, 4, 84-99. [CrossRef]

48. Guadagnoli, E.; Velicer, W.F. Relation of sample size to the stability of component patterns. Am. Psychol. Assoc. 1988, 103, 265-275. [CrossRef]

49. Comrey, A.L. Factor-analytic methods of scale development in personality and clinical psychology. Am. Psychol. Assoc. 1988, 56, 754-761. [CrossRef]

50. Tabachnick, B.G.; Fidell, L.S.; Ullman, J.B. Using Multivariate Statistics, 5th ed.; Pearson: Boston, MA, USA, 2007 ; pp. 481-498.

51. Williams, B.; Onsman, A.; Brown, T. Exploratory factor analysis: A five-step guide for novices. Australas. J. Paramed. 2010, 8. [CrossRef]

52. Eun, H.J.; Kwon, T.W.; Lee, S.M.; Kim, T.H.; Choi, M.R.; Cho, S.J. A study on reliability and validity of the Korean version of impact of event scale-revised. J. Korean Neuropsychiatr. Assoc. 2005, 44, 303-310.

53. Baek, H.S.; Lee, K.U.; Joo, E.J.; Lee, M.Y.; Choi, K.S. Reliability and validity of the Korean version of the Connor-Davidson Resilience Scale. Psychiatry Invest. 2010, 7, 109-115. [CrossRef] [PubMed]

54. Boateng, G.O.; Neilands, T.B.; Frongillo, E.A.; Melgar-Quiñonez, H.R.; Young, S.L. Best practices for developing and validating scales for health, social, and behavioral research: A primer. Front. Public Health 2018, 6, 149. [CrossRef]

55. Kang, H.C. A guide on the use of factor analysis in the assessment of construct validity. J. Korean Acad. Nurs. 2013, 43, 587-594. [CrossRef]

56. Kaiser, H.F. The application of electronic computers to factor analysis. Educ. Psychol. Meas. 1960, 20, 141-151. [CrossRef]

57. Cattell, R.B. The scree test for the number of factors. Multivar. Behav. Res. 1966, 1, 245-276. [CrossRef]

58. O'connor, B.P. SPSS and SAS programs for determining the number of components using parallel analysis and Velicer's MAP test. Behav. Res. Methods Instrum. Comput. 2000, 32, 396-402. [CrossRef]

59. Linden, M.; Baumann, K.; Lieberei, B.; Rotter, M. The post-traumatic embitterment disorder Self-Rating Scale (PTED Scale). Clin. Psychol. Psychother. 2009, 16, 139-147. [CrossRef]

60. Holmes, E.A.; Creswell, C.; O'Connor, T.G. Posttraumatic stress symptoms in London school children following September 11, 2001: An exploratory investigation of peri-traumatic reactions and intrusive imagery. J. Behav. Exp. Psychiatry 2007, 38, 474-490. [CrossRef] [PubMed]

61. Jones, N.M.; Garfin, D.R.; Holman, E.A.; Silver, R.C. Media use and exposure to graphic content in the week following the Boston marathon bombings. Am. J. Community Psychol. 2016, 58, 47-59. [CrossRef] [PubMed]

62. Lantz, M.S.; Buchalter, E.N. Posttraumatic stress. Geriatrics 2001, 56, 35-36. [PubMed]

63. Galovski, T.E.; Mott, J.; Young-Xu, Y.; Resick, P.A. Gender differences in the clinical presentation of PTSD and its concomitants in survivors of interpersonal assault. J. Interpers Violence 2011, 26, 789-806. [CrossRef]

64. Hourani, L.; Williams, J.; Bray, R.; Kandel, D. Gender differences in the expression of PTSD symptoms among active duty military personnel. J. Anxiety Disord. 2015, 29, 101-108. [CrossRef] [PubMed] 
65. Yehuda, R. Post-traumatic stress disorder. N. Engl. J. Med. 2002, 346, 108-114. [CrossRef]

66. Zhao, N.; Zhou, G. Social media use and mental health during the COVID-19 pandemic: Moderator role of disaster stressor and mediator role of negative affect. Appl. Psychol. Health Well Being 2020, 12, 1019-1038. [CrossRef] 